\title{
HISTÓRIAS DE MANASSÉS: \\ O RIO DE JANEIRO PELO OLHAR DE UM CRONISTA-LEITOR
}

\section{HISTORIES OF MANASSÉS:}

\section{THE RIO DE JANEIRO BY THE EYES OF THE COLUMNIST-LECTURER}

Sílvia Maria Azevedo*

RESUMO: Cronista moderno, dublê de leitor, era nos jornais diários de onde Manassés - pseudônimo com o qual Machado de Assis assinava suas crônicas na Ilustração Brasileira (1876-1878) -, extraía a maior parte das notícias que irá comentar com os leitores da revista ilustrada de Henrique Fleiuss. É sob o ângulo desse cronista, "puro contador de histórias", que se pretende captar as imagens do Rio de Janeiro da época. PALAVRAS-CHAVE: Machado de Assis, cronista, leitor, Ilustração Brasileira (1876-1878).

ABSTRACT: Columnist fashionable, double as of lecturer, period of time at the newspapers diaries as of where Manassés pseudonym with which Machado de Assis was sign your chronicles at the Illustration Brazilian (1876-1878), extracted the larger part of the news which will comment with the lecturers from the magazine illustrated as of Henrique Fleiuss. Is under the angle he might give Columnist "counter as of histories", that if he pretends grab the images from the Rio de Janeiro of the time.

KEY WORDS: Machado de Assis, columnist, lecture, Illustration Brazilian (1876-1878).

* Professor Assistente Doutor - Departamento de Literatura. Faculdade de Ciências e Letras UNESP/Assis. Email: silrey@uol.com.br. 



\section{HISTÓRIAS DE MANASSÉS: O RIO DE JANEIRO PELO OLHAR DE UM CRONISTA-LEITOR}

(...) o encanto do velho Rio, as ruas de nomes evocativos, sombreadas do passado, que ele nunca descreveu com a minuciosa objetividade balzaquiana, mas recriou, ao sugerir em dois ou três traços vivos a alma de um ambiente. Sua sombra integrou-se na toponímia da cidade velha, espalhada entre o mar e os morros. Mas tudo por acidente, dado de graça e de caminho, pois ninguém menos plástico do que ele, mais desdenhoso do pitoresco e cioso da essência psicológica. (...) Não pintou, portanto, o Rio do seu tempo, nem a gente, nem o ambiente do seu tempo, senão para poder mais livremente cultivar a sua paixão da análise psicológica, desabafo indireto e velado, às vezes inconsciente, do seu pessimismo. Augusto Meyer.

Quando convidado por Henrique Fleiuss para escrever as crônicas da Ilustração Brasileira (1876-1878), Machado de Assis já tinha alguma experiência no gênero, pois que durante a década de 1860, havia colaborado nos periódicos Diário do Rio de Janeiro, O Futuro e Semana Ilustrada, aqui, compartilhando com outros escritores o pseudônimo "Dr. Semana". Embora não fosse estreante, nem por isso era pequena a responsabilidade de Machado ao assumir as crônicas da Ilustração, tendo em vista a expansão do gênero, ao lado das charges e caricaturas, nas folhas diárias e revistas, na segunda metade do século XIX. 
O pseudônimo escolhido pelo escritor para assinar a seção - Manassés -, nome de um chefe de tribo israelita, filho mais velho de José do Egito, e que, em hebraico, significa "o que faz esquecer" ou "votado ao esquecimento”, revelaria a intenção, na interpretação de Raimundo Magalhães Júnior, de camuflar a sua participação no jornal $A$ Época, de Joaquim Nabuco, para não desgostar o mestre e amigo, José de Alencar, que na ocasião travava cerrada polêmica com Nabuco nas páginas de $O$ Globo, de Quintino Bocaiúva (1981, v. II, p. 184).

Se em função desse contexto, a suposta intenção de anonimato de Machado de Assis se fazia representar na escolha simbólica no pseudônimo, logo nas primeiras crônicas Manassés faz questão de ser lembrado como alguém que priva com personalidades ilustres, como o diplomata e escritor chileno Guilherme Blest Gana que, de volta ao seu país, era homenageado com um jantar de despedida, no Rio de Janeiro. Ao jantar compareceu a fina flor da intelectualidade brasileira, dentre os mencionados, Quintino Bocaiúva e o visconde de Rio Branco. Amigo de longa data de Blest Gana, é com orgulho mal disfarçado que o cronista diz guardar um retrato do diplomata, acompanhado de "graciosa quadrinha", que não hesita em transcrever, na crônica de $1^{\circ}$ de julho de 1876 :

\section{"Verás en ese retrato \\ De semejanza perfecta, \\ La imagen de un mal poeta \\ Y un poco peor litterato."}

Da mesma forma, na crônica de 15 de julho do mesmo ano, identifica-se no comentário ao banquete oferecido pelos norte-americanos residentes na Corte em comemoração ao centenário da independência dos Estados Unidos, o propósito de o cronista da Ilustração Brasileira marcar presença em festividade que passaria a integrar o calendário cívico norte-americano. Está claro que era função de Manassés comparecer e representar a revista de Fleiuss nos eventos importantes da Corte, de modo a comentá-los, depois, com os leitores. Mas a voz que fala - "Também eu fui ao banquete" - não simplesmente informa, mas, antes, diz - "Também eu estive lá” -, o advérbio no início da frase dando ênfase à inclusão do cronista que, não tendo ido aos Estados Unidos com a comitiva de D. Pedro II para visitar a Exposição Universal de Filadélfia, podia participar das celebrações do centenário da independência norte-americana, mesmo ficando no Rio de Janeiro. 
Mas, em geral, Manassés é cronista avesso a festas e bailes, o que não o impede de fazer referência às "boas noites de diversão" da "fashion fluminense", como as reuniões semanais na mansão de Diogo Velho e o sarau realizado no palacete do conselheiro Nabuco, na segunda quinzena de agosto de 1877, ocasião em que se comemorou o aniversário da filha do jurisconsulto, como irá comentar:

"Sei que lá reinaram a graça e a elegância; que a animação foi geral e constante; que a festa terminou depois das 4 horas da madrugada. O cotilhão foi brilhantemente dirigido pelo Sr. Dr. Sizenando Nabuco."

Outro baile elegante ao qual o cronista da Ilustração Brasileira não compareceu foi a festa anual da Secretaria de Estrangeiros, que ocorria na residência do visconde de Meriti (mais tarde, marquês de Abrantes), na Glória, sempre no dia 15 de agosto. Naquela de 1876, no lugar da informação, Manassés concentrou-se em representar os preparativos daqueles que vão à festa, na ficcionalização de duas espécies de leitoras e de um amigo:

"No momento em que escrevo estas linhas, espreito cá de longe a leitora a preparar-se para a festa da Glória. Há duas sortes de leitoras: a que vai ao outeiro, toma água benta, vê o fogo de artifício, e vai a pé para casa, se não pilha um bond; e a que sai de casa às 9 horas para ir ao baile da Secretaria de Estrangeiros. Uma e outra preparam-se neste instante; sonham com a festa, pedem a Nossa Senhora que não mande chuva. A segunda espera que a Clemence lhe apronte o vestido a tempo e hora oportuna; a primeira dá os últimos pontos na saia da que há de estrear hoje de tarde.

(...)

Um amigo meu recusa dançar há [sic] seis semanas, com o plausível motivo de que não quer gastar as pernas. Só fala em francês para conversar com os diplomatas; estuda a questão do Oriente para dizer alguma coisa ao ministro da Inglaterra. Traz de cor a frase com que há de cortejar o Ministro da Itália e o chefe da legação pontifícia. Ao primeiro dirá: Italia farà da se. Ao segundo: Super hanc petran..."

\footnotetext{
${ }^{1}$ A edição das crônicas de Machado de Assis publicadas na Ilustração Brasileira, compreendendo atualização ortográfica, introdução, notas, índice onomástico e imagens, foi organizada por mim, e será publicada pela editora Ateliê.
} 
Assim como o amigo, Manassés também não foi, naquele ano, às corridas do Prado Fluminense, por dois motivos (como faz questão de justificar): por ter os pés "moídos" (talvez porque ande muito a pé), e por não gostar de corrida de cavalos nem de touros. Principalmente, por não gostar do cavalo, apesar de o animal ter sido cantado pelos poetas e dos muitos serviços prestados ao homem, como vai dizer na crônica de 15 de agosto de 1876:

"Não gosto? detesto-o: acho-o o mais intolerável dos quadrúpedes. É um fátuo, é pérfido, é animal corrupto. Sob pretexto de que os poetas o têm cantado, de um modo épico ou de um modo lírico; de que é nobre; amigo do homem; de que vai à guerra; de que conduz moças bonitas; de que puxa coches; sob pretexto de uma infinidade de complacências que temos para com ele, o cavalo parece esmagar-nos [com] sua superioridade. Ele olha para nós com desprezo, relincha, prega-nos sustos, faz Hipólito em estilhas. É um elegante perverso, um tratante bem educado: nada mais."

Mesmo quando comparece aos concertos de música (pelos quais o cronista demonstra predileção), como o da Sociedade Filarmônica e o da Orquestra Sinfônica do Rio de Janeiro, ocorridos na quinzena de 1876, Manassés limita-se a comentar, tal como no baile da Secretaria de Estrangeiros, o entorno da festa: neste caso, o grande número de pessoas que assistiram aos dois espetáculos musicais e os fogos de artifício do Largo do Machado.

$\mathrm{Na}$ maioria das vezes, Manassés mostra-se afastado de certos espaços mais populares, o que compreende também os espetáculos aí apresentados, como a exibição da célebre Maria Spelterini, que chegou ao Brasil, em outubro de 1877, depois de gloriosa passagem pelos Estados Unidos, quando atravessou as cataratas do Niágara. No Rio de Janeiro, os retratos na "funâmbula" vão estar em toda parte, como vai se queixar Manassés, em crônica de $1^{\circ}$ de setembro de 1877. As acrobacias da Spelterini deviam fazer o público carioca perder o fôlego, mas é pouco provável que o cronista tenha ido vê-la, conforme havia prometido na crônica anterior, talvez irritado pela propaganda em torno da ginasta, talvez porque aquele tipo de apresentação não o interessasse, como se pode depreender do comentário breve e reticente: "Esta funâmbula bonita e ágil, mestre na arte de usar a marona, tem abalado uma parte da população, que ainda admira os feitos 
ginásticos. Não sei se o Tartufo teria tanta concorrência. Talvez não; e daí... pode ser que sim... pode ser".

A referência à comédia de Molière em meio ao comentário sobre o espetáculo da Spelterini, identifica o universo literário de Manassés e aproxima expressões culturais que fazem parte de universos distantes, aqui, com a intenção, talvez, de apontar a degradação cultural no Rio de Janeiro - "Não sei se o Tartufo teria tanta concorrência" -, que o cronista da Ilustração Brasileira registra também nos palcos cariocas, tomados por operetas e mágicas, às quais em geral não vai assistir.

Da mesma forma que o contato com a Spelterini se fez por intermédio da imagem da acrobata que o cronista diz estar por toda parte da cidade, o Carnaval é outra diversão que não o leva às ruas do Rio de Janeiro, nem a comentar e descrever os bailes e desfiles das associações carnavalescas. Carnaval, para Manassés, resume-se à palavra "bisnaga". Se um dia o Carnaval morrer - hipótese que considera na crônica de 15 de fevereiro de 1877, na entrada da Quaresma -, no lugar da festa popular ficará "bisnaga", "um problema filológico" para os lingüistas do futuro, que quebrarão a cabeça para entender a etimologia da palavra, aventando interpretações as mais disparatadas. Guardião da memória das coisas e do tempo, o cronista da Ilustração tem a chave do enigma: foi o "bom e galhofeiro" Gomes de Freitas, "o único autor da palavra" - a quem o cronista passa a se dirigir - "[tu] que aconselhavas a bisnaga e a grande arnica, no tempo em que o esguicho apareceu, por cujo motivo puseram o nome popularizado por ti”. Esta, a origem da palavra, que só hão de saber "os grandes sábios do futuro", "se certo número da Ilustração chegar até eles”.

Assim, ao mesmo tempo em que se mostra empenhado em registrar a memória do Rio de Janeiro, Manassés sabe que a informação a respeito da etimologia do termo "bisnaga" corria o risco de não entrar para a História, dado o caráter volátil do veículo de circulação da crônica, o que se reflete igualmente no sentido simbólico do pseudônimo: Manassés, “o que faz esquecer". Em todo caso, o cronista fazia a sua parte, ao chamar a seção que assinava de "História de Quinze Dias", depois, "História de Trinta Dias", quando a Ilustração Brasileira, em 1878, passa de quinzenal a mensal, títulos que recuperam a origem, ou antes, a memória da palavra crônica, que implicava a noção de tempo, presente no próprio termo, que procede do grego khronos, remetendo à época em que a crônica era crônica histórica, como a medieval: "uma narração de fatos históricos segundo uma ordem 
cronológica, (...), e por essa via se tornou uma precursora da historiografia moderna." (ARRIGUCCI JÚNIOR, 1985, p. 43).

Os títulos da seção de Manassés, por sua vez, reforçam o sentido mais acentuadamente temporal das crônicas, sem que o espaço deixe de ser convocado. Num primeiro momento, as indicações espaciais definem a fixação realista das crônicas, ancorando-as no real, produzindo a impressão de que refletem o não-texto. Por outro lado, a representação do espaço nas crônicas de Manassés não se limita à descrição dos lugares, nem o espaço configura-se enquanto exterioridade diante da qual o cronista se coloca. Tomese a crônica de 15 de setembro de 1876, a respeito das péssimas condições de calçamento da Rua das Laranjeiras (por sinal, endereço de Machado de Assis, depois de casado com Carolina), que, em dias de chuva

“(...) fica pouco menos lamacenta que qualquer sítio do Paraguai. Também é verdade que duas pessoas, necessitadas de comunicar uma à outra, com urgência, podem vir desde o Cosme Velho até o largo do Machado, cada uma de sua banda, sem achar lugar em que atravessem a rua. Finalmente não se contesta que sair de bond, em qualquer outra da dita rua, é empresa só comparável à passagem do mar Vermelho, que ali é escuro. Tudo isso é verdade. Mas em compensação, que bonito nome! Laranjeiras! Faz lembrar Nápoles: tem uns ares de idílio; a sombra de Teócrito deve por força vagar naquelas imediações.”

Os procedimentos retóricos empregados na representação da lamacenta Rua das Laranjeiras - a comparação, o humor, a ironia -, deslocam a nota realista, e aquilo que era não-texto transforma-se em texto. Da mesma forma, como se verá em seguida, a atuação do cronista no papel de leitor de jornais, reforça o sentido textual da fixação do espaço.

Empenhado em resgatar a memória de sua cidade, nem por isso Manassés sai às ruas à procura de tipos e fatos pitorescos da cena urbana carioca, a exemplo do cronista-viajante Joaquim Manuel de Macedo, autor de três "relatos de viagem" (SÜSSEKIND, 1990, p. 227), sobre a cidade do Rio de Janeiro, a saber: A carteira de meu tio (1855), Um passeio pela cidade do Rio de Janeiro (1862) e Memórias da rua do Ouvidor (1878). Manassés, que está mais para Xavier de Maistre do que Macedo, é o cronista que viaja ao redor de seu gabinete, à espera que as notícias (metonímias da cidade), cheguem até ele, o que o transforma em "um puro contador de histórias" como vai dizer no início da crônica de 15 de março de 1877, parte da qual se transcreve: 
"Mais dia menos dia demito-me deste lugar. Um historiador de quinzena, que passa os dias no fundo de um gabinete escuro e solitário, que não vai às touradas, às câmaras, à rua do Ouvidor, um historiador assim é um puro contador de histórias".

"Um puro contador de histórias", que é também leitor de "coisas miúdas" extraídas dos jornais, na figuração do cronista da Ilustração Brasileira. Olhar atento, tesoura na mão, Manassés seleciona, recorta e transcreve as notícias que mais lhe chamam a atenção, procedimento que lhe permite escrever a crônica do Rio de Janeiro, na forma do intertexto. Como a nota de um jornal a respeito de duas "filhas de Eva" que foram a um baile no teatro D. Pedro II, trajadas de maneira indecorosa. O "artiguinho" foi transcrito na crônica de 15 de janeiro de 1877:

"Duas das mais grosseiras e desmoralizadas criaturas têm freqüentado os bailes, causando os mais desagradáveis episódios aos que têm tido a infelicidade de aproximar-se-lhes.

Essas duas filhas de Eva acharam-se no Teatro D. Pedro II vestidas em femmes de la hâle (filha de Madame Angot), e hoje também dizem que lá se acharão...

Seria bom que o empresário tivesse algum fiscal encarregado de vigiá-las, para evitar incidentes tais como se deram no domingo passado." (itálico no original)

O exemplo reitera o perfil de cronista de fundo de redação, permitindo reconhecer no comentário lacônico que acompanha a transcrição - "Ó isca! Ó costumes!” -, o crítico severo das mágicas de onde foi extraída a comparação em referência ao comportamento visto como indecoroso das duas mulheres, freqüentadoras dos bailes do teatro D. Pedro II.

Em geral, os anúncios da seção "a pedidos” do Jornal do Comércio eram os preferidos de Manassés. Quanto mais extravagantes, mais o cronista parecia se deliciar, como no caso daquele transcrito, com as devidas aspas, na crônica de 15 de maio de 1877: "Pede-se para trocar o segundo volume do romance de Rocambole, porque falta um grande número de páginas (64 a 81), assim como no fim a ordem das páginas está invertida”.

Em seguida, o comentário do cronista é o do leitor de bom senso que, diante de tal disparate, demonstra a maior perplexidade:

"Isto ao pé da letra, é um disparate. Trocar um volume, porque tem falta de páginas, é proposta que se faça a alguém? Além de falta de páginas, há páginas 
invertidas, isto é, um defeito além do outro, e que só vem agravar o primeiro. Finalmente, não diz onde nem quem deseja trocar o volume."

É quando entra em cena uma senhora - "espírito agudo e velhaco" (inspirada talvez nas proezas mentais do detetive Auguste Dupin, de Edgar Allan Poe) -, que vai ajudar o cronista a desvendar o enigma:

"O anúncio é um rendez-vous. Rocambole e a troca de volume, são apenas o fio que liga a oração secreta. Fiquemos no número de páginas que faltam: 64 a 81; fiquemos na circunstância das páginas invertidas do fim. 64 compõe-se de um 6 e um 4; 6 e 4, dez. São as horas do rendez-vous. 81 é um 8 e um 1: invertidos (páginas invertidas no fim), dão 18: dia do rendez-vous. Assim temos: no dia 18 , às 10 horas, espere-me."

A interpretação, ou antes, a leitura daquela senhora, tão ou mais estapafúrdia que o anúncio publicado no jornal, põe sob suspeita a nota transcrita na crônica, mesmo com o aparato das aspas, só havendo um jeito de saber se Manassés mentiu ou não que é consultar o número do Jornal do Comércio de maio de 1877.

Publicado ou não o "a pedidos", o objeto de ironia do cronista é o Rocambole de Ponson de Terrail, verdadeira febre que toma conta do Rio de Janeiro em 1859, quando o folhetim é anunciado pelo Jornal do Comércio, o que pelo visto ainda acontece em 1877, quando haveria leitores dispostos a comprar um volume da obra em que faltavam várias páginas e com páginas invertidas.

A popularidade do Rocambole, por sua vez, representa não apenas o leitor aficionado àquele gênero de leitura como também o espaço físicosocial dentro do qual esse leitor se insere. Não é de admirar que Manassés, que não freqüenta, como se viu, espaços mais populares nem participa dos eventos que aí acontecem, faça questão de informar em crônica de 15 de janeiro de 1877 que não é leitor do Rocambole, que certo dia leu no Jornal do Comércio estar de volta ao Brasil (daí o "anúncio" da outra crônica): "Certo é que nunca o vi mais gordo. Eu devo confessar este pecado a todos os ventos do horizonte; eu (cai-me a cara no chão), eu... nunca li o Rocambole, estou virgem dessa Ilíada de realejo".

Além dos anúncios, as notícias policiais também eram do interesse de Manassés, a exemplo do "parricídio do Largo do Depósito", examinado na 
crônica de $1^{\circ}$ de setembro de 1876 , cuja causa alguns queriam que fosse "um livro de Dumas": "Santo Deus!" - exclama um cronista aparentemente surpreso - "se basta um livro para armar o braço de um homem, façamos deste mundo uma biblioteca de Alexandria; é mais sumário do que separar os livros maus dos bons".

A acusação é tanto mais absurda quanto propícia à recriação do crime, sob o ângulo dos efeitos nocivos da leitura, com o respaldo da notícia de um jornal francês, que saiu em 1869, acerca de um criminoso que aos dezenove anos passou a gostar de ler os processos judiciais, e nem por isso alguém se lembrou de associar aquela leitura e os assassinatos cometidos pelo jovem. Esta interpretação, no entanto, até que seria verossímil, dada a repercussão do romance de Alexandre Dumas Filho, L'Affaire Clemenceau, publicado em 1866, no qual o escritor francês, como se sabe, defende a tese de que o marido tem o direito de matar a mulher que o desonrou. Dumas Filho chegou a abordar a questão num panfleto, Tue-la, que despertou grande polêmica na França (BRITO BROCA, 1992, p. 194-195).

A simulação do julgamento de Dumas Filho, que vem ao Rio de Janeiro responder pela acusação que recai sobre seu livro, funciona como elo e chave interpretativa quanto aos delitos praticados, no presente e no passado, pelo assassino carioca e pelo criminoso francês. $\mathrm{O}$ interrogatório entre o acusador e o acusado, em obediência à verossimilhança da situação imaginada, se dá em francês, pois que desconhecendo Dumas o português, era o juiz obrigado a falar a língua do réu:

- Monsieur, vous avez écrit un méchant livre...

- Ma modestie ne dit pas le contraire.

- Vous vous tromper, monsieur; je ne dis pas sous le rapport littéraire; je parle de la portée morale de ce livre, un livre dangereux, corrupteur...

- Pourtant, monsieur le juge, l'Académie...

- L'Académie n'est pas tenue d’avoir des moeurs irréprochables. Ce livre, monsieur, vient de commetre un crime...

- Bah!

- Oui, ce livre est jugé et condamné.

- Qu’on le même aux galères!

- Pas lui, mais vous. Lui, il sera brulé par la main du bourreau; vous irez composer d’autres ouvrages dans un endroit très poètiques, quoique peu littéraire. 
- J’en appelle...

- Vous êtes un monstre!

É possível pensar que o diálogo em francês atenda não somente à verossimilhança interna da cena criada, mas também à externa, enquanto caracterização do afrancesamento da sociedade carioca letrada da época, o domínio da língua de Molière figurando, ainda, como marca de civilização a acentuar, por contraste, a barbárie do crime praticado no Rio de Janeiro.

Além da língua, a França exportou para o Brasil o romance realista que, como se sabe, irá explorar a relação espaço-personagem em termos de causalidade, perspectiva que também pode ter sido empregada pelos jornais do Rio de Janeiro que, além da notícia sobre o assassinato, talvez tenham aproveitado para criticar o alto índice de criminalidade na cidade, associando-o às péssimas condições de vida da população mais pobre que morava em espaços degradados.

Ora, Manassés afasta-se tanto da concepção de espaço concebida pela literatura realista quanto da perspectiva jornalística calcada na notícia, preocupada na reconstituição do crime o que levaria o repórter ao local. É o oposto o que faz o cronista da Ilustração Brasileira que, como se viu, viaja ao redor de seu gabinete. Talvez por isso, a crônica que, nesse aspecto, faz lembrar dos artigos de Machado de Assis a respeito do romance O primo Basílio de Eça de Queirós, ofereça o mínimo de indicações "geográficas" - "o parricídio do Largo do Depósito" -, simples ponto de referência a despertar a imaginação do leitor-cronista, que concebe o crime motivado não pela ação do espaço sobre o parricida carioca, mas por outra causa: a leitura de "um livro de Dumas", que acaba sendo L'Affaire Clemenceau.

A situação imaginada - um tribunal diante do qual se apresenta o escritor francês -, por um lado, garante a concentração espacial da narrativa sob a forma do diálogo, por outro, imprime a nota desviante em relação à concepção de espaço do romance realista, aí compreendida a descrição, que não tem lugar na crônica. Ao mesmo tempo, o desvio proposto permitiu internalizar a crítica aos pressupostos estéticos do Realismo, atualizada enquanto situação ficcional. Por fim, o exame do crime do Largo do Depósito sob o ponto de vista da leitura mimetiza a atuação do cronista Manassés como leitor de jornais, ângulo pelo qual são captadas as imagens do Rio de Janeiro da época. 


\section{Referências Bibliográficas}

ARRIGUCCI JÚNIOR, Davi. "Fragmentos sobre a crônica”. Boletim bibliográfico. Biblioteca Mário de Andrade. São Paulo, v. 46, nº. 1/4, p. 43-53, jan./dez., 1985.

BROCA, Brito. "Um romance esquecido". Horas de leitura: $1^{\text {a }}$. e $2^{\text {a }}$. séries [coordenação Alexandre Eulálio]. Campinas, SP: Editora Unicamp, 1992.

MAGALHÃES JÚNIOR, Raimundo. Vida e obra de Machado de Assis. $2^{\circ}$. vol. Rio de Janeiro: Civilização Brasileira: INL, 1981.

SÜSSEKIND, Flora. O Brasil não é longe daqui: o narrador, a viagem. São Paulo: Companhia das Letras, 1998. 
